\title{
Immunohistochemical Expression of Androgen and Estrogen Receptors and their Prognostic Significance in Urothelial Carcinoma of the Urinary Bladder
}

\author{
MANAR EL-NADY, M.Sc.; ALIAA ATEF, M.D.; HANAN EL-SHENAWY, M.D. and AFAF EL-SHAFEI, M.D. \\ The Department of Pathology, Faculty of Medicine, Tanta University, Tanta, Egypt
}

\begin{abstract}
Background: Bladder cancer is the most common malignancy affecting the urinary tract. It is the fourth most common cancer in men and the ninth most common in women worldwide. It is at least three times more common in males than females suggesting the role of sex hormones in initiation and progression of bladder cancer. The purpose of this study is to detect the immunohistochemical expression of $(A R)$ and $\left(E_{\beta}\right)$ in urothelial carcinoma and correlate their expression with the known prognostic parameters of urothelial carcinoma to illustrate their prognostic role.
\end{abstract}

Material and Methods: Seventy cases of urothelial carcinoma of the urinary bladder in the form of radical cystectomy (15 specimens) and Transurethral Resection of the Tumour (TURT) (55 specimens) were collected retrospectively. They were stained by $\mathrm{H} \& \mathrm{E}, \mathrm{AR}$ and $\mathrm{ER}_{\beta}$ for immunohistochemical study. The relationship between their expression and the available clinicopathological features were evaluated.

Results: $\mathrm{AR} / \mathrm{ER}_{\beta}$ was positive in $(62.9 \% / 52.9 \%$ respectively) of the studied cases. Significantly lower expression of $A R /$ higher expression of $E_{\beta}$ were found in high-grade tumours $(52.4 \% / 66.7 \%$ respectively) ( $p$-value $=0.025,0.005$ respectively) and in muscle invasive tumours $(48.4 \% / 71 \%$ respectively) ( $p$-value $=0.026,0.007$ respectively).

Conclusions: $\mathrm{AR}$ and $\mathrm{ER}_{\beta}$ expression were significantly correlated with the tumour grade and degree of invasion suggesting the suitability of $A R$ and $E_{\beta}$ as prognostic markers of urothelial carcinoma. High AR expression was associated with favorable prognosis of urothelial carcinoma in contrast to high $\mathrm{ER}_{\beta}$ expression which was associated with bad prognosis of urothelial carcinoma.

Key Words: Androgen - Estrogen - Receptor-Bladder cancer - Urothelial -Immunohistochemistry - Prognosis.

\section{Introduction}

BLADDER Cancer (BC) is the most common malignancy in the urinary tract and Urothelial Carcinoma (UC) is the predominant histological

Correspondence to: Dr. Manar El-Nady, The Department of Pathology, Faculty of Medicine, Tanta University, Tanta, Egypt type [1]. Urothelial carcinoma is responsible for death of 165000 persons annually worldwide according to the International Agency for Research on Cancer and the World Health Organization, with the highest mortality rates among Egyptian males [1] . It is more common in middle and old age [2] Females presented with the disease at older age than males [3]. Urothelial carcinoma is the 4 th most common cancer in men and the 9 th in women worldwide [1]. In Gharbia government, bladder cancer ranks the $3 \mathrm{rd}$ in both sexes being the $2 \mathrm{nd}$ in males and the 7 th in females [4]. It is at least three times more common in men than women [1]. Excessive exposure to carcinogens, e.g. cigarette smoke and industrial chemicals, has been suggested to be a cause of higher incidence of bladder cancer in males [5]. Even, after controlling these carcinogens, men still have a higher risk than women [6]

In the light of the previous facts, existence of a relationship between sex hormones and cancer bladder is suggested. Data from animal and human studies suggested that sex hormones have important physiological effects on the lower urinary tract [7] Sex steroids act by binding to their receptors in target cells including Androgen Receptors (ARs) and Estrogen Receptors (ERs) [8]. These receptors have been detected in normal bladder urothelium [9]. The AR and ER signaling pathways affect bladder cancer development and progression [8]. Bladder cancer management has remained essentially unchanged, with no new effective treatment options approved in the past few decades [10]. Treatment of non-muscle invasive bladder cancer involves transurethral resection of the tumour followed by intravesical chemo-or immunotherapy but muscleinvasive cancer requires radical cystectomy and systemic chemotherapy [11]. Many patients receiving BCG develop either local or systemic side 
effects [10]. The effects of sex hormones on bladder cancer cells need to be studied, which might help in development of prognostic biomarkers and new therapies.

\section{Material and Methods}

This study was carried out on 70 cases of urothelial carcinoma of the urinary bladder ( 56 males and 14 females, age ranged between 28 and 88 years). These cases were collected retrospectively from the archives of Pathology Department, Faculty of Medicine, Tanta University and from some private laboratories during the period of the research from 2015 to 2017 and patients' data were obtained from files of surgery and oncology reports. Approval from Research Ethics Committee (REC), Faculty of Medicine, Tanta University, was taken antecedent to conducting study. Tissue specimens were in the form of radical cystectomy (15 specimens) and Transurethral Resection of the Tumour (TURT) (55 specimens). After histopathological evaluation, tumors were graded according to the WHO 2016 of urothelial neoplasia, and they were classified as low grade and high grade urothelial carcinoma. Tumors were staged according to American Joint Committee (AJCC), TNM pathologic staging of urinary bladder. Immunohistochemical staining was performed on $10 \%$ formalin fixed, paraffin embedded tissue blocks for evaluation of AR and ERP expression. Sections were immunohistochemically labeled, using primary antibodies to AR (EPR3778 clone, rabbit monoclonal antibody, 0.1ml, dilution 1:50; Dako, Egypt) and ER P (AR441 clone, mouse monoclonal antibody, $0.1 \mathrm{Jml}$, dilution 1:300; Abcam, Egypt). AR and ER P staining was detected as brownish nuclear staining and all these stains were manually scored by the German Immunoreactive Score based on multiplying percentage of immunoreactive cells $\{0 \%=(0), 1-10 \%=(+1)$, $11-50 \%=(+2), 51-80 \%=(+3), 81-100 \%=(+4)\}$ by staining intensity $\{$ Negative $(+0)$, weak $(+1)$, moderate $(+2)$, strong $(+3)\}$. Scores (range $0-12$ ) were considered negative $(0 ; 0-1)$, weakly positive $(+1$; $2-4)$, moderately positive (+2; 6- 8) and strongly positive $(+3 ; 9-12)$ [8] . Chi-square test and Spearman's correlation coefficient test were used as tests of significance to evaluate the association between categorized variables and $p$-value $<0.05$ was considered statistically significant.

\section{Results}

Different clinicopathological criteria of 70 bladder specimens were evaluated (Table 1), then correlated with AR and ER P expression (Table 2).
Table (1): Clinicopathological characteristics of the studied cases.

\begin{tabular}{|c|c|c|}
\hline Clinicopathological features & No. & $\%$ \\
\hline \multicolumn{3}{|l|}{ 1- Age: } \\
\hline$<50$ & 13 & 18.6 \\
\hline 50 & 57 & 81.4 \\
\hline \multicolumn{3}{|l|}{ 2- Gender: } \\
\hline Male & 56 & 80 \\
\hline Female & 14 & 20 \\
\hline \multicolumn{3}{|l|}{ 3- Size: } \\
\hline$<3 \mathrm{~cm}$ & 55 & 78.6 \\
\hline $3 \mathrm{~cm}$ & 15 & 21.4 \\
\hline \multicolumn{3}{|l|}{ 4- Multiplicity: } \\
\hline Single & 36 & 51.4 \\
\hline Multiple & 34 & 48.6 \\
\hline \multicolumn{3}{|l|}{ 5- Grade: } \\
\hline Low & 28 & 40 \\
\hline High & 42 & 60 \\
\hline \multicolumn{3}{|l|}{ 6- Degree of muscle invasion: } \\
\hline NMI (Ta,T1) & 39 & 55.7 \\
\hline MI (T2, T3, T4) & 31 & 44.3 \\
\hline \multicolumn{2}{|l|}{ specimens: } & \\
\hline pT2a & 1 & 6.7 \\
\hline pT2b & 6 & 40 \\
\hline pT3a & 2 & 13.3 \\
\hline pT3b & 1 & 6.7 \\
\hline pT4a & 4 & 26.6 \\
\hline pT4b & 1 & 6.7 \\
\hline \multicolumn{3}{|l|}{ specimens: } \\
\hline Without & 11 & 73.3 \\
\hline With & 4 & 26.7 \\
\hline \multicolumn{3}{|l|}{ 9- Concomitant CIS: } \\
\hline Without & 68 & 97.1 \\
\hline With & 2 & 2.9 \\
\hline \multicolumn{3}{|l|}{ 10- Perineural invasion: } \\
\hline Without & 61 & 12.9 \\
\hline With & 9 & 87.1 \\
\hline \multicolumn{3}{|l|}{ 11- Lympho-vascular invasion: } \\
\hline Without & 62 & 88.6 \\
\hline With & 8 & 11.4 \\
\hline \multicolumn{3}{|l|}{ 12- Recurrence after treatment: } \\
\hline Without & 67 & 95.7 \\
\hline With & 3 & 4.3 \\
\hline $\begin{array}{l}\text { CIS }: \text { Carcinoma in Situ. } \\
\text { NMI : Non-Muscle Invasive. } \\
\text { MI : Muscle Invasive. }\end{array}$ & & \\
\hline
\end{tabular}


Table (2): AR and ERP expression correlated with clinicopathological characteristics.

\begin{tabular}{|c|c|c|c|c|c|c|}
\hline \multirow{2}{*}{ Variables } & \multicolumn{3}{|c|}{$\mathrm{AR}$} & \multicolumn{3}{|c|}{$\mathrm{ER}_{\beta}$} \\
\hline & $-\mathrm{ve}(\mathrm{n}=26)$ & $+v e(n=44)$ & $p$-value & $-v e(n=33)$ & $+v e(n=37)$ & $p$-value \\
\hline \multicolumn{7}{|l|}{ 1- Age: } \\
\hline$<50(13)$ & $6 \quad(46.2 \%)$ & $7 \quad(53.8 \%)$ & 0.456 & $6 \quad(46.1 \%)$ & $7 \quad(53.9 \%)$ & 0.529 \\
\hline $50(57)$ & $20(35.1 \%)$ & $37(64.9 \%)$ & & $31(54.4 \%)$ & $26(45.6 \%)$ & \\
\hline \multicolumn{7}{|l|}{ 2- Gender: } \\
\hline Male (56) & $20(35.7 \%)$ & $36(64.3 \%)$ & 0.621 & $27(48.2 \%)$ & $29(51.8 \%)$ & 0.119 \\
\hline Female (14) & $6 \quad(42.9 \%)$ & $8 \quad(57.1 \%)$ & & $10(71.4 \%)$ & $4 \quad(28.6 \%)$ & \\
\hline \multicolumn{7}{|l|}{ 3-Size: } \\
\hline$<3 \mathrm{~cm}(55)$ & $17(30.9 \%)$ & $38(69.1 \%)$ & $0.039^{*}$ & $30(54.6 \%)$ & $25(45.4 \%)$ & $0.018^{*}$ \\
\hline$\geq 3 \mathrm{~cm}(15)$ & $9(60 \%)$ & $6(40 \%)$ & & $3 \quad(20 \%)$ & $12(80 \%)$ & \\
\hline \multicolumn{7}{|l|}{ 4- Multiplicity: } \\
\hline Single (36) & $12(33.3 \%)$ & $24(66.7 \%)$ & 0.497 & $22(61.1 \%)$ & $14(38.9 \%)$ & $0.016^{*}$ \\
\hline Multiple (34) & $14(41.2 \%)$ & $20(58.8 \%)$ & & $11(32.4 \%)$ & $23(67.6 \%)$ & \\
\hline \multicolumn{7}{|l|}{ 5- Grade: } \\
\hline Low (28) & $6 \quad(21.4 \%)$ & $22(68.6 \%)$ & $0.025^{*}$ & $19(67.9 \%)$ & $14(32.1 \%)$ & $0.005^{*}$ \\
\hline High (42) & $20(47.6 \%)$ & $22(52.4 \%)$ & & $9 \quad(33.3 \%)$ & $28(66.7 \%)$ & \\
\hline \multicolumn{7}{|c|}{ 6- Degree of invasion: } \\
\hline NMI (39) & $10(25.6 \%)$ & $29(74.4 \%)$ & $0.026^{*}$ & $24(61.5 \%)$ & $15(38.5 \%)$ & $0.007 *$ \\
\hline MI (31) & $16(51.6 \%)$ & $15(48.4 \%)$ & & $9(29 \%)$ & $22(71 \%)$ & \\
\hline \multicolumn{7}{|c|}{ 7- Invasion level (1 5): } \\
\hline $\mathrm{T} 2(7)$ & $4(57.1 \%)$ & $3(42.9 \%)$ & $0.047 *$ & $3(42.9 \%)$ & $4(57.1 \%)$ & $0.042 *$ \\
\hline T3 (3) & $2(66.6 \%)$ & $1(33.3 \%)$ & & $1(33.3 \%)$ & $2(66.7 \%)$ & \\
\hline $\mathrm{T} 4(5)$ & $4(80 \%)$ & $1(20 \%)$ & & $0(0 \%)$ & $5(100 \%)$ & \\
\hline \multicolumn{7}{|c|}{ 8- L.N metastasis (1 5): } \\
\hline Without (11) & $7(63.6 \%)$ & $4(36.4 \%)$ & 0.679 & $3(27.3 \%)$ & $8(72.7 \%)$ & 0.929 \\
\hline With (4) & $3(75 \%)$ & $1(25 \%)$ & & $1(25 \%)$ & $3(75 \%)$ & \\
\hline \multicolumn{7}{|c|}{ 9- Concomitant CIS: } \\
\hline Without (68) & $25(36.8 \%)$ & $43(63.2 \%)$ & 0.703 & $33(48.5 \%)$ & $35(51.5 \%)$ & 0.175 \\
\hline With (2) & $1 \quad(50 \%)$ & $1 \quad(50 \%)$ & & $0(0 \%)$ & $2(100 \%)$ & \\
\hline \multicolumn{7}{|c|}{ 10- Perineuralinvasion: } \\
\hline Without (61) & $20(32.8 \%)$ & $41(67.2 \%)$ & $0.049^{*}$ & $31(50.8 \%)$ & $30(49.2 \%)$ & $0.033^{*}$ \\
\hline With (9) & $6 \quad(66.7 \%)$ & $3 \quad(33.3 \%)$ & & $2(22.2 \%)$ & $7 \quad(77.8 \%)$ & \\
\hline \multicolumn{7}{|l|}{ 11- $L-V$ invasion: } \\
\hline Without (62) & $21(33.9 \%)$ & $41(66.1 \%)$ & 0.115 & $31(50 \%)$ & $31(50 \%)$ & $0.041 *$ \\
\hline With (8) & $5 \quad(62.5 \%)$ & $3(37.5 \%)$ & & $2(25 \%)$ & $6(75 \%)$ & \\
\hline \multicolumn{7}{|l|}{ 12- Recurrenc: } \\
\hline Without (67) & $24(35.8 \%)$ & $43(64.2 \%)$ & 0.278 & $33(49.3 \%)$ & $34(50.7 \%)$ & 0.279 \\
\hline With (3) & $2(66.7 \%)$ & $1 \quad(33.3 \%)$ & & $0(0 \%)$ & $3(100 \%)$ & \\
\hline
\end{tabular}

AR expression was detected in 44 cases $(62.9 \%)$ (12 weak, 18 moderate, 14 strong). AR expression was not significantly correlated with the age and gender $(p$-value $=0.456,0.621$ respectively $)$. There was a significant correlation between AR expression and tumour size $(p$-value $=0.039)$.

AR expression was not significantly correlated with the number of urinary bladder masses ( $p$ value $=0.497)$. AR expression was significantly correlated to tumour grade $(p$-value $=0.026)$. AR expression was higher in low grade cases $(78.5 \%)$ Fig. (1A) than high-grade cases (52.4\%) Fig. (1B).
AR expression was significantly correlated with degree of muscle invasion $(p$-value $=0.026)$ with higher AR expression in NMI tumours (pTa, pT1) (74.4\%) opposite to only $48.4 \%$ of MI (pT2, pT3, pT4). In cystectomy specimens, there was a significant association between AR expression and the level of invasion $(p$-value $=0.046)$ with negative correlation coefficient ( $\mathrm{r} s$ ) denoting loss of AR expression in more invasive tumours. AR expression wasn't significantly correlated with lymph node metastasis in cystectomy specimens and lesions with concomitant CIS ( $p$-value $=0.679$, 0.703 respectively). There was a significant corre- 
lation between AR expression and perineural invasion ( $p$-value $=0.049)$. AR expression wasn't significantly correlated with lympho-vascular invasion ( $p$-value $=0.115)$. In the three cases that showed recurrence after treatment with TUR followed by intravesical BCG instillation, two primary cases (66.7\%) were AR negative and one case (33.3\%) was $\mathrm{AR}+2$.

$\mathrm{ER}_{\mathrm{P}}$ expression was positive in 37 cases (52.9\%) (11 weak, 20 moderate, 6 strong). ER P expression wasn't significantly correlated with the age and gender ( $p$-value $=0.592,0.119$ respectively). ERP expression was significantly correlated with tumor size and multiplicity ( $p$-value $=0.018,0.016$ respectively). ERP expression was significantly correlated to the tumour grade in the studied cases ( $p$-value $=0.005)$. Higher positive ER P in highgrade cases $(66.7 \%)$ than low-grade cases $(32.1 \%)$ Fig. (2A,B).

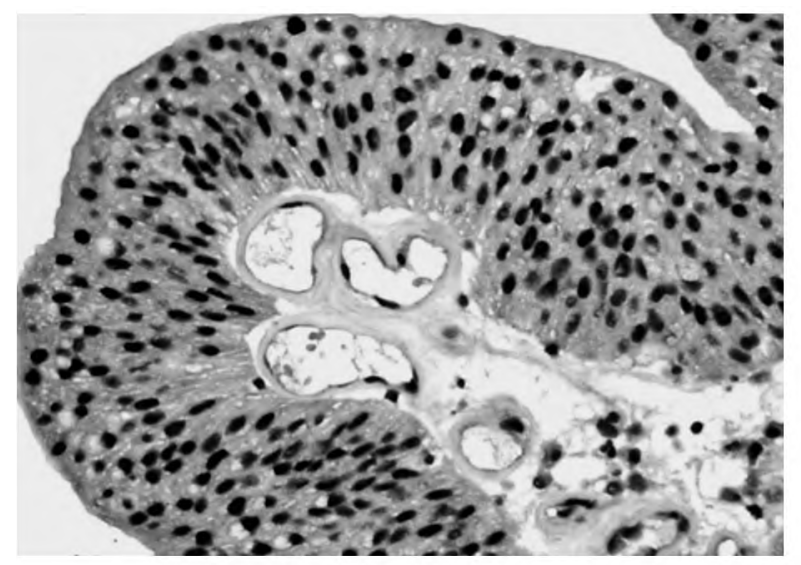

(A)
ERP expression was significantly correlated with degree of muscle invasion ( $p$-value $=0.007)$ with lower ERP expression in NMI tumours (38.5\%) opposite to $71 \%$ of MI Fig. (3A). In cystectomy specimens, there was a significant association between ERP expression and invasion level ( $p$-value $=0.033)$ with positive correlation coefficient $\left(r_{s}\right)$ denoting high ERP expression in more invasive tumours. In cystectomy specimens with lymph node metastasis, three cases (75\%) showed positive expression, but it did not reach the statistically significant level ( $p$-value=0.929) Fig. (3B).

Lesions with concomitant CIS showed no significant correlation with ERP expression ( $p$-value= $0.175)$. ERP expression was significantly correlated with perineural and lympho-vascular invasion ( $p$ value $=0.033,0.041$ respectively). The three cases $(100 \%)$ that showed recurrence after treatment were ERP positive, but it did not reach the statistically significant level $(p$-value $=0.279)$.

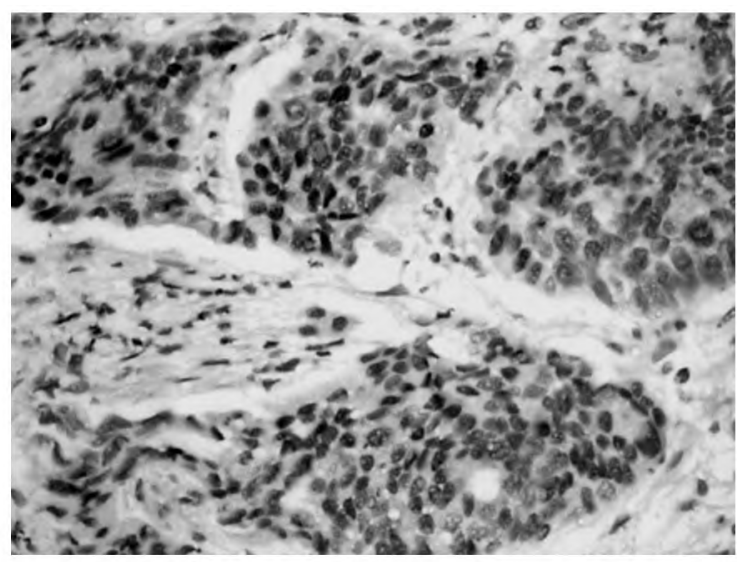

(B)

Fig. (1): (A) Low grade non-invasive papillary UC showing strong positive AR immunoreactivity (+3). (X400). (B) High grade UC infiltrating lamina propria with weak positive AR immunoreactivity $(+1)$. (X400).

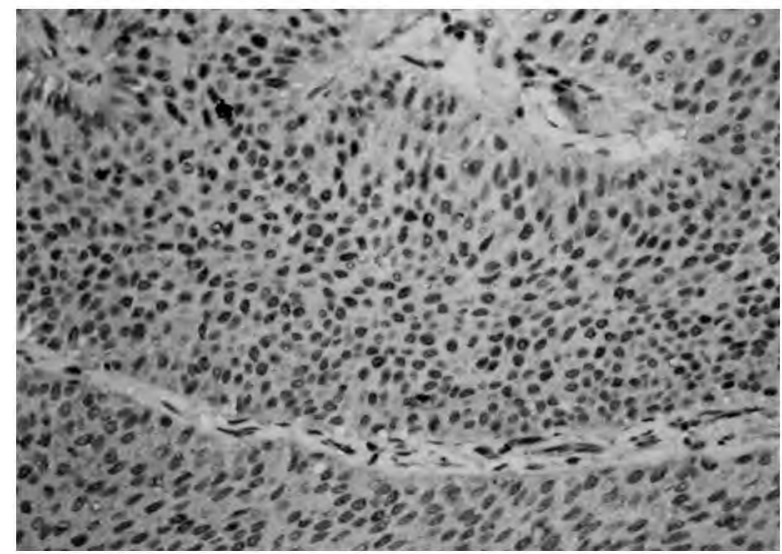

(A)

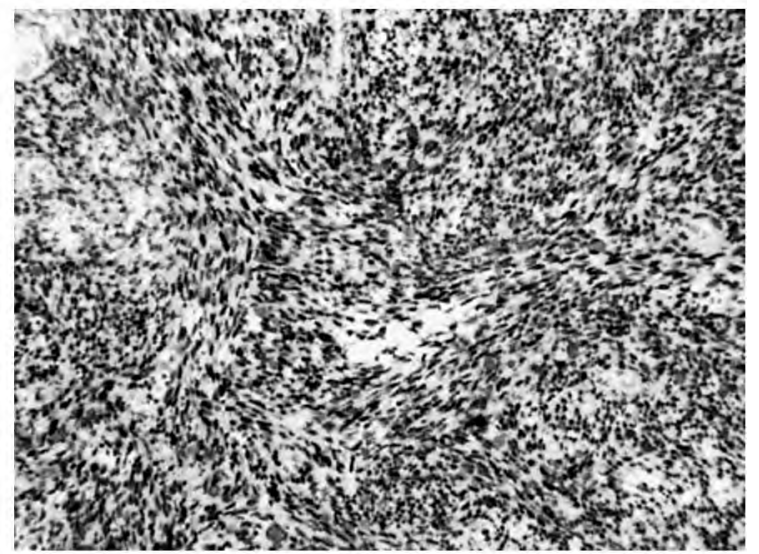

(B)

Fig. (2): (A) Low grade non-invasive UC showing weak positive ER P immunoreactivity (+1). (X200). (B) High grade UC with sarcomatoid differentiation showing strong positive ER P (+3). (X200). 


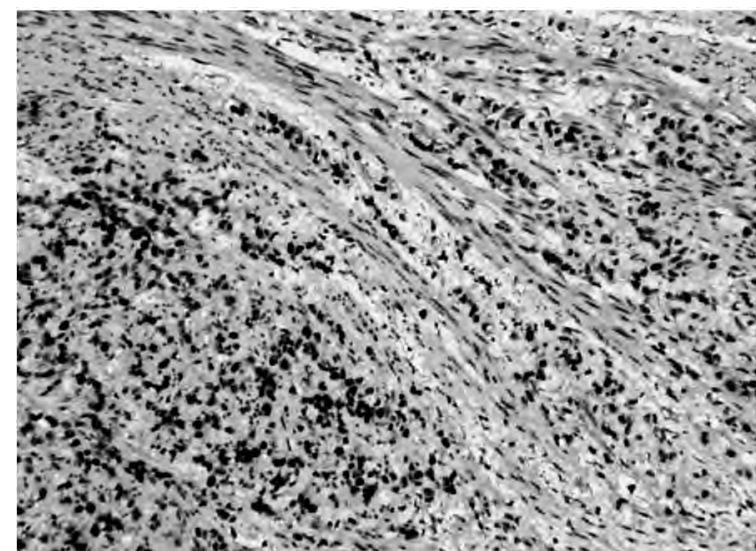

(A)

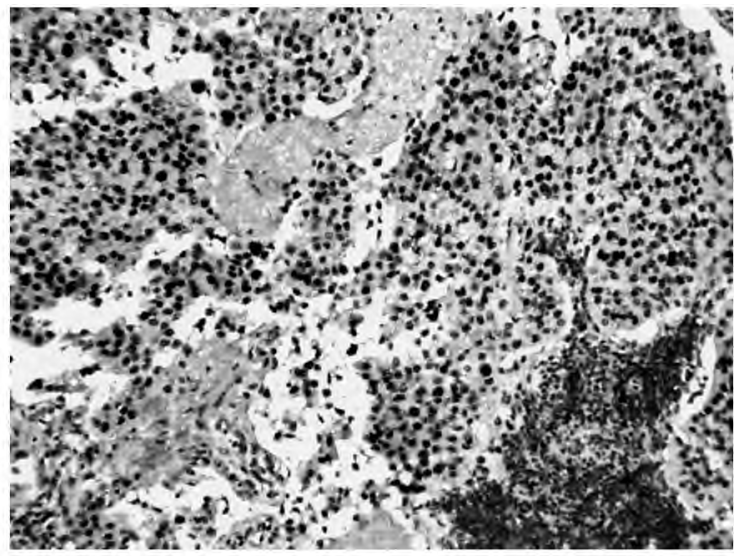

(B)

Fig. (3): (A) High grade UC infiltrating muscularis propria showing strong positive ER $\beta(+3)$. (X200). (B) Lymph node metastasis of UC showing strong positive $\mathrm{ER}_{\beta}(+3)$. (X200).

\section{Discussion}

$\mathrm{AR}$ and $\mathrm{ER}_{\beta}$ are members of nuclear receptor superfamily [3]. Androgen/androgen receptor signaling pathway up-regulates the expression of active $\beta$-catenin also affects p53 tumor suppressor functions [12]. A retrospective study involving patients who received androgen deprivation therapy for prostate cancer showed a significantly lower incidence of subsequent BC [13]. Higher AR expression associated with low grade tumour, nonmuscle invasive tumour, size less than $3 \mathrm{~cm}$ and absent perineural invasion. Loss of AR expression was reported in cases with lymph node metastasis and risk of recurrence, but it did not reach the statistically significant level. From that, higher AR expression was associated with better prognosis of urothelial carcinoma which was in agreement with some studies $[\mathbf{8 , 1 4 , 1 5}]$. In contrast to a study reported that $\mathrm{AR}$ expression had no prognostic value (124) and another one reported bad prognosis in AR-positive patients with higher rate of invasion, metastasis and recurrence [17]. High AR expression was significantly correlated with low-grade cases $(p$-value $=0.026)$ which was in agreement with Miyamoto, et al., ( $p$-value $=0.023)[8]$. In contrast, Mashhadi, et al., reported a significant association between AR expression and high-grade tumors ( $p$ value $=0.024)$ [17]. High AR expression was significantly correlated with NMI cases $(p$-value $=0.026)$ which was in agreement with Miyamoto, et al. (2012) $(p$-value $=0.018)$ [8]. In contrast to Mir, et al. (2011) who concluded loss of AR expression in NMI tumours $(p$-value $=0.048)[16]$.

$\mathrm{ER}_{\beta}$ is the dominant estrogen receptors expressed in urothelium [10]. Estrogen affects cell cycle progression through up-regulation of both cyclin D1 and cyclin E [18].
Higher $\mathrm{ER}_{\beta}$ expression in the current study was significantly correlated with high grade tumours, more invasive tumours, size more than $3 \mathrm{~cm}$, multiple lesions in the urinary bladder, tumours with perineural and lympho-vascular invasion. High $\mathrm{ER}_{\beta}$ expression was detected in cases with lymph node metastasis and risk of recurrence, but it did not reach the statistically significant level. From that, high $\mathrm{ER}_{\beta}$ expression was associated with bad prognosis of urothelial carcinoma which was in agreement with most studies $[\mathbf{8 , 1 9}]$. In contrast Bangmin, et al., [20] reported favorable prognosis in $\mathrm{ER}_{\beta}$ positive patients. High $\mathrm{ER}_{\beta}$ expression was significantly correlated with high-grade tumours ( $p$-value $=0.005)$ which was in agreement with Miyamoto, et al. (2012) ( $p$-value <0.001) [8] . In contrast, Bangmin, et al., reported a significant association between $\mathrm{ER}_{\beta}$ expression and low-grade tumors $(p$-value $=0.037)$ [20]. High $\mathrm{ER}_{\beta}$ expression was significantly correlated with MI cases ( $p$ value $=0.007)$ which was in agreement with Miyamoto, et al. (2012) ( $p$-value <0.001) [8] . In contrast to Kontos, et al., who reported higher positive ER expression in NMI tumours ( $p$-value $=0.001)$ with good prognosis [21].

\section{Conflict of interest:}

None declared.

\section{References}

1- SEBASTIEN A., JACQUES F., ISABELLE S., et al.: Bladder Cancer Incidence and Mortality: A Global Overview and Recent Trends. European Urology, 71: 96-108, 2017.

2- SCOSYREV E., NOYES K., FENG C., et al.: Sex and racial differences in bladder cancer presentation and mortality. Cancer, 115: 68-74, 2011. 
3- HARUN F., JOSHUA A., EUGENE K., et al.: Impact of gender on bladder cancer incidence, staging, and prognosis. World J. Urol., 29: 457-63, 2011.

4- ELSHIKH E., ANAN I., EBAID A., et al.: The National Cancer Registry in Egypt: A retrospective Cross Sectional Epidemiological Study. Value in Health, 18: 437, 2015.

5- CUMBERBATCH M., ROTA M., CATTO J., et al.: The role of tobacco smoke in bladder and kidney carcinogenesis: A comparison of exposures and meta-analysis of incidence and mortality risks. Eur. Urol., 70: 458-66, 2016.

6- BURGER M., CATTO J., DALBAGNI G., et al.: Epidemiology and risk factors of urothelial bladder cancer. Eur. Urol., 63: 234-41, 2013.

7- ALI Y., METE C., MUHAMMET K., et al.: Can Reproductive Characteristics Predict Bladder Cancer in Women with Haematuria? Asian Pac. J. Cancer Prev., 14: 510710, 2013.

8- MIYAMOTO H., YAO J., CHAUX A., et al.: Expression of androgen and oestrogen receptors and its prognostic significance in urothelial neoplasm of the urinary bladder. B.J.U. Int., 109: 1716-26, 2012.

9- CHAVALMANE A., COMEGLIO P., MORELLI A., et al.: Sex steroid receptors in male human bladder: Expression and biological function. J. Sex Med., 7: 2698-713, 2010.

10- GUILHERME G., GEORGIOS G., CAROLYN L., et al.: Effects of Androgen and Estrogen Receptor Signaling Pathways on Bladder Cancer Initiation and Progression. Bladder Cancer, 2: 127-37, 2016.

11- BABJUK M., BURGER M., ZIGEUNER R., et al.: EAU guidelines on non-muscle invasive urothelial carcinoma of the bladder: Update 2013. Eur. Urol., 64: 639-53, 2013.

12- HSU J., HSU I., XU D., et al.: Decreased tumorigenesis and mortality from bladder cancer in mice lacking urothelial androgen receptor. Am. J. Pathol., 182: 1811-20, 2013.
13- SHIOTA M., YOKOMIZO A., TAKEUCHI A., et al.: Secondary bladder cancer after anticancer therapy for prostate cancer: Reduced comorbidity after androgendeprivation therapy. Oncotarget., 6: 14710-9, 2015.

14- JONG N., SUNG P., SANG L., et al.: Prognostic Value of Sex-Hormone Receptor Expression in Non-MuscleInvasive Bladder Cancer. Yonsei Med. J., 55: 1214-21, 2014.

15- WILLIAMS E., HIGGINS J., SANGOI A., et al.: Androgen receptor immunohistochemistry in genitourinary neoplasms. Int. Urol. Nephro., 47: 81-5, 2015.

16- MIR C., SHARIAT S., VAN DER KWAST T.H., et al.: Loss of androgen receptor expression is not associated with pathological stage, grade, gender or outcome in bladder cancer: A large multi-institutional study. B.J.U. Int., 108: 24-30, 2011.

17- MASHHADI R., POURMAND G., KOSARI F., et al.: Role of steroid hormone receptors in formation and progression of bladder carcinoma: A case-control study. Urol. J., 11: 1968-73, 2014.

18- JIAN T., ZUN Y., DAVID F., et al.: Roles of estrogen receptor $\mathrm{a}$ and $\mathrm{b}$ in modulating urothelial cell proliferation. Endocrine-Related Cancer, 15: 3 51-64, 2008.

19- KAUFFMAN B., ROBINSON M., DOWNES M., et al.: Role of androgen receptor and associated lysinedemethylase coregulators, LSD1 and JMJD2A, in localized and advanced human bladder cancer. Molecular Carcinogenesis, 50: 93 1-44, 2013

20- BANGMIN H., DI C., YIFENG J., et al.: Estrogen receptor [ $3\left(\mathrm{ER}_{\beta}\right)$ is a novel prognostic marker of recurrence survival in non-muscle-invasive bladder cancer potentially by inhibiting cadherin switch. World J. Urol., 32: 149-55, 2014.

21- KONTOS S., KOMINEA A., MELACHRINOU M., et al.: Inverse expression of estrogen receptorp-and nuclear factor-kB in urinary bladder carcinogenesis. Int. J. Urol., 179: 801-9, 2010.

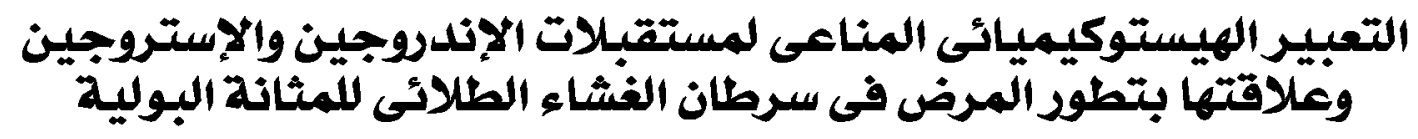

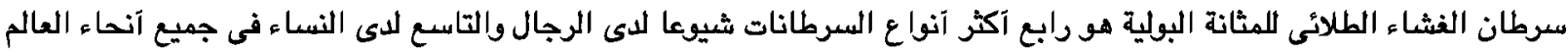

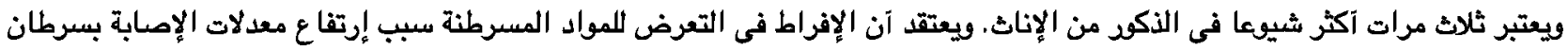

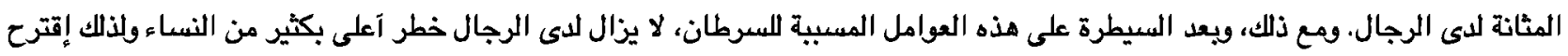

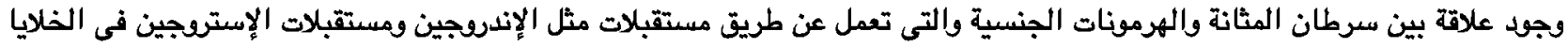

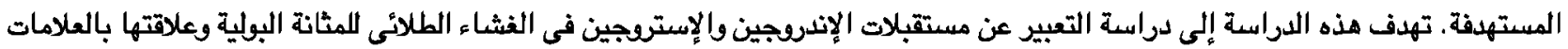

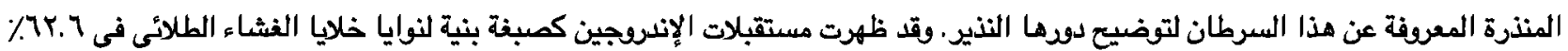

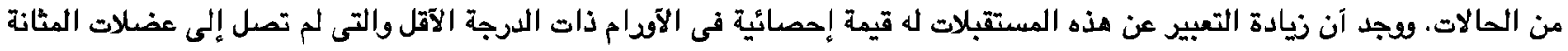

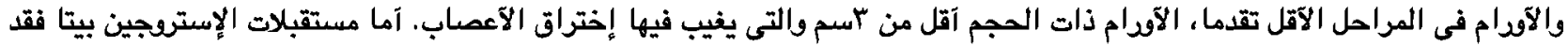

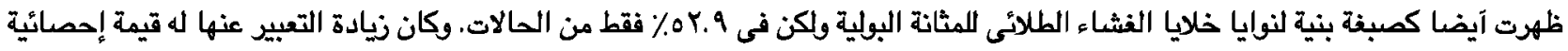

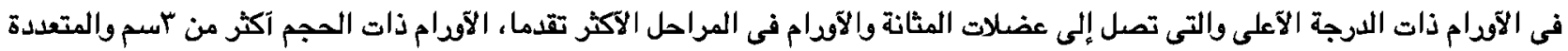

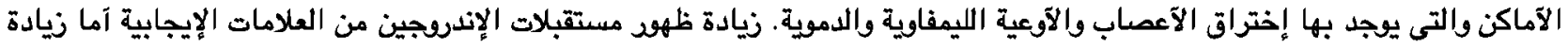
الإستروجين بيتا فإنه من العلامات المنترة العيئة. 